\title{
THE EFFECT OF EXPONENTIAL/COSINE HYPERBOLIC/
}

\section{POLYNOMIAL/ KAISER WINDOW PARAMETERS CG-ICG-ENBW-SL ON THE SNR IMPROVEMENT OF MST RADAR SIGNALS}

\author{
B.Ramesh Reddy ${ }^{1}$, A.Subbarami Reddy ${ }^{2}$, P.Chandrashekar Reddy ${ }^{3}$ \\ ${ }^{1}$ Professor and HOD, Dept of ECE, LBR College of Engineering, Andhra Pradesh, India, brrece73@gmail.com \\ ${ }^{2}$ Principal, Srikalahasteeswara Institute of Technology, Andhra Pradesh, India \\ ${ }^{3}$ Professor, Dept of ECE, JNTU College of Engineering, Hyderabad, Andhra Pradesh, India
}

\begin{abstract}
In this paper, the effect of Exponential/Cosine Hyperbolic/Polynomial/Kaiser window parameters Coherent Gain (CG), Incoherent Power Gain (ICG), Equivalent Noise Band Width (ENBW) and Scalloping Loss (SL) on the SNR values of MST Radar returns has been investigated. Six sets of multibeam observations of the lower atmosphere made by the Indian Mesosphere-StratosphereTroposphere (MST) RADAR are used for the result analysis. Prior to the Fourier Transform, the in-phase and quadrature components of the Radar echo samples are weighted with Exponential/Cosine Hyperbolic/Polynomial/Kaiser window Functions. It is observed that, with the increase in the parameter " $\alpha$ " of Exponential and Cosine Hyperbolic Window and parameter " $m$ " of Polynomial Window increases ENBW and SL, but decreases in CG and ICG. This observation can be used to establish in improving the Signal to Noise Ratio (SNR) of MST RADAR signals. From this study it is reported that, the window e parameter " $\alpha=6 / \mathrm{m}=4$ " can be suggested for optimum results of SNR improvement in MST RADAR signals. The optimum widow parameter " $\alpha / m$ " in turn yields optimum Exponential window parameters as " $C G=0.4768, I C G=0.3495, E N B W=1.5371, S L=0.8536$ ”, Cosine Hyperbolic window parameters as " $C G=0.4769$, ICG $=0.3495, E N B W=1.5366$, $S L=0.8535$ ”, Polynomial window parameters as " $C G=0.5719$, $I C G=0.4799$, $E N B W=1.4673, S L=0.8011$ ”, and Kaiser window parameters as “CG=0.4991, ICG=0.3660, ENBW=1.4695, SL=0.8410". Which corresponds to optimum mail lobe width and side lobe attenuation to increase the SNR of MST Radar noisy data..
\end{abstract}

Index Terms: CG, ICG, ENBW, SL, SNR, FFT, Spectral Analysis.

\section{INTRODUCTION}

This paper presents the effect of Exponential / Cosine Hyperbolic / Polynomial / Kaiser window parameters Coherent Gain (CG), Incoherent Power Gain (ICG), Equivalent Noise Band Width (ENBW) and Scalloping Loss (SL) on the SNR of Radar returns and proposed an optimum value of " $\alpha$ or $\mathbf{m}$ " with which data may be weighed using above window functions. Harmonic analysis with the discrete Fourier transform (DFT) plays a central role in radar signal processing. The significance of using data weighting windows with the DFT [1]-[3] plays an important role in resolving the frequency components of the signal buried under the noise. Since the use of an inappropriate window can lead to corruption of the principal spectral parameters, hence it is important to consider the criteria by which the choice of data weighting window to be selected for optimum results [4]. Here we will observe the effects of " $\alpha$ or $\mathbf{m}$ " in recently proposed adjustable windows based on the Exponential [5] and Cosine Hyperbolic [6] and Polynomial [7] Window Functions on the SNR of RADAR returns.

\section{THE DATA WEIGHTING WINDOWS}

There are many types of data weighting windows, which are used to select finite number of samples of impulse response. Among them some are fixed length windows and some adjustable width windows. Here our presentation is on adjustable windows. Windows are time-domain weighting functions that are used to reduce Gibbs' oscillations resulting from the truncation of a Fourier Series [8]. Their roots date back over one-hundred years to Fejer's averaging technique for a truncated Fourier Series and they are employed in a variety of traditional signal processing applications including power spectral estimation, beam forming, and digital filter design.

In Digital Signal Processing we have Rectangular Window, Hanning Window, Hamming Window, Blackmann Window, Barlett Window or Triangular Window and Kaiser Window. Windows have been employed to aid in the classification of cosmic data [9]-[10] and to improve the reliability of weather prediction models [11]. It is well known [1]-[3] that the application of FFT to a finite length data gives rise to leakage and picket fence effects. Weighting the data with suitable 
windows can reduce these effects. However the use of the data windows other than the rectangular window affects the bias, variance and frequency resolution of the spectral estimates [2]-[3]. In general, variance of the estimate increases with the use of a window. An estimate is to be consistent if the bias and the variance both tend to zero as the number of observations is increased. Thus, the problem associated with the spectral estimation of a finite length data by the FFT techniques is the problem of establishing efficient data windows or data smoothing schemes. The observed Doppler spectra therefore represent convolutions of the Fourier transforms of the original signals with those of the data weighting windows projected onto the discrete frequencies [1]. Data windows are used to weight time series of the in-phase and quadrature phase components of the radar return samples prior to applying the DFT.

\section{SPECTRAL LEAKAGE}

For signal frequencies, observed through the rectangular window, which do not correspond exactly to one of the sampling frequencies, the pattern is shifted such that non-zero values are projected onto all sampling frequencies. This phenomenon of spreading signal power from the nominal frequency across the entire width of the observed spectrum is known as spectral leakage [1], [12]-[13]. The effect of data windowing on the SNR improvement of MST Radar signals has been reported in the literature [14]-[22]. By properly selecting the shape parameters of the adjustable windows, it is made possible to achieve the SNR improvement with the optimum shape parameters [15]-[22].In literature many windows have been proposed [1], [23]-[27]. They are known as suboptimal solutions, and the best window is depending on the applications.

Windows can be categorized as fixed or adjustable [28]. Fixed windows have only one independent parameter, namely, the window length which controls the main-lobe width. Adjustable windows have two or more independent parameters, namely, the window length, as in fixed windows, and one or more additional parameters that can control other window characteristics [1],[24]-[25],[29]-[30]. The Kaiser and Saramaki windows [23]-[24] have two parameters and achieve close approximations to discrete prolate functions that have maximum energy concentration in the main lobe. The DolphChebyshev window [25],[29] has also two parameters and produces the minimum main-lobe width for a specified maximum side-lobe level. With adjusting their two independent parameters, namely the window length and the shape parameter, it can be controlled the spectral parameters of main lobe width and ripple ratio for various applications. Kaiser window has a better sidelobe roll-off characteristic than the other well known adjustable windows such as DolphChebyshev [19] and Saramaki [28], which are special cases of ultra-spherical window [27], but obtaining a window which performs higher sidelobe roll-off characteristics for the same main lobe width than Kaiser Window will be useful.

The Atmospheric Radar returns considered to be composed of a quasi-monotonic (atmospheric) signal superimposed on a background of white noise. As might be expected, since the signal does not correspond exactly to one of the sampling frequencies, the forms of the signal portions of the spectra follow those of the envelopes of the side lobe maxima. Spectral leakage from the signal therefore exceeds noise level, evaluated by the method of Hildebrand and Sekhon [31], and a corresponding underestimate of Signal-to-Noise Ratio.

\section{PROPOSED WINDOW FUNCTIONS}

There are many window functions, which are used in signal processing applications like, Rectangular Window, Hanning Window, Hamming Window, Blackmann Window, Barlett Window, etc. Here we will discuss about Exponential window and Cosine Hyperbolic window and Polynomial window and Kaiser Window.

\subsection{Exponential Window}

For discrete time, the Exponential window [5] is defined in the following equations in terms of uniformly spaced samples.

$$
w_{e}(n, \alpha)=\left\{\begin{array}{c}
\frac{\exp \left(\alpha \sqrt{1-\left(\frac{2 n}{N-1}\right)^{2}}\right)}{\exp (\alpha)},|n| \leq \frac{N-1}{2}---(1) \\
0, \text { otherwis e }
\end{array}\right.
$$

Where ' $\alpha$ ' is the adjustable shape parameter

\subsection{Cosine Hyperbolic Window}

Cosine Hyperbolic Window [6] can be defined as

$$
w_{c}(n, \alpha)=\left\{\begin{array}{c}
\frac{\operatorname{Cosh}\left(\alpha \sqrt{1-\left(\frac{2 n}{N-1}\right)^{2}}\right)}{\operatorname{Cosh}(\alpha)},|n| \leq \frac{N-1}{2}--(2) \\
0, \text { otherwise }
\end{array}\right.
$$

Where ' $\alpha$ ' is the adjustable shape parameter

\subsection{Polynomial Window}

Continuous time Polynomial window function [7] can be defined as

$$
w_{m}(t)=1-K_{m} \sum_{n=0}^{m} A_{m, n} t^{2 m-n+1}
$$


Where

$\mathrm{m}=$ Order of the window function

$K_{m}=\frac{(2 m+1) !(-1)^{m}}{(m !)^{2}}$

$A_{m, n}=\frac{(-1)^{n m} C_{n}}{2 m-n+1}$

${ }^{m} C_{n}=\frac{m !}{n !(m-n) !}$

The expression for the window function in the interval $[-1,1]$ instead of $[0,1]$, the absolute value of $\mathrm{t}$ can be used as the independent variable rather than t, i.e.,

$w_{m}(t)=1-K_{m} \sum_{n=0}^{m} A_{m n}|t|^{2 m-n+1}-$ for $[-1 \leq t \leq 1]$

The DT form of the window function can be obtained by replacing " $t$ " using the following relation.

$$
t=\frac{2 k}{(N-1)} \text { for }-\frac{(N-1)}{2} \leq k \leq \frac{(N-1)}{2}
$$

The Fourier transformation for the window function wm (t) can be given by

$W_{m}(w)=\int_{-\infty}^{\infty} w_{m}(t) e^{-i w t} d t$

The recurrence formula for frequency response is expressed as

$W_{m}(w)=2 K_{m} \sum_{n=0}^{m} I_{2 m-n+1} A_{m, n} \frac{(2 m-n+1)(2 m-1)}{w^{2}}, m>0$

4.4 Kaiser Window

$$
\begin{aligned}
& I_{0}=\frac{\sin (w)}{w} \\
& I_{1}=\frac{\cos (w)-w \sin (w)-1}{w^{2}}
\end{aligned}
$$

In discrete time domain, Kaiser Window is defined by [23]

$$
w_{k}(n, \alpha)=\left\{\begin{array}{c}
\frac{I_{0}\left(\alpha \sqrt{1-\left(\frac{2 n}{N-1}\right)^{2}}\right)}{I_{0}(\alpha)},|n| \leq \frac{N-1}{2}---(12) \\
0, \text { otherwis } e
\end{array}\right.
$$

Where ' $\alpha$ ' is the adjustable shape parameter, and $\operatorname{I} 0(x)$ is the modified Bessel function of the first kind of order zero and it is described by the power series expansion as

$$
I_{0}(x)=1+\sum_{k=1}^{\infty}\left(\frac{1}{k !}\left(\frac{x}{2}\right)^{k}\right)^{2}
$$

The two parameters useful to obtain the desired amplitude response pattern of the above defined windows are the length of the sequence $\mathrm{N}$ and a shape parameter " $\alpha$ or $\mathrm{m}$ ". As the No of FFT points considered in the MST Radar data of each range bin is fixed to 512, the window length $\mathrm{N}$ is fixed to 512 . Hence the shape parameter " $\alpha$ or $m$ " can be only varied to achieve the desired pattern of the magnitude response of the window used.

As the shape parameter" $\alpha$ or m" increases, the side lobe level of the magnitude response decreases at the cost of main lobe width [1]-[3]. In this paper we have investigated the SNR variation of MST radar data as a function of the shape parameter " $\alpha$ or $m$ " with respect to side lobe level and main lobe width variations. The results of SNR improvement of the MST Radar data are evaluated in terms of Mean Value Below Zero (MVBZ) SNR and Mean Value Above Zero (MVAZ) SNR [15]-[22].

\section{WINDOW PERFORMANCE ANALYSIS}

Performance of window functions can be computed from figure of merits, like Coherent Gain(CG), Incoherent Power Gain(ICG), Equivalent Noise Band Width(ENBW) and Scalloping Loss(SL).

\subsection{Coherent Gain}

Averaging of the window function $\mathrm{w}(\mathrm{nT})$ is called Coherent Gain. It can be computed from the formula

$$
C G=\frac{1}{N} \sum_{n} w(n T)
$$

For the rectangular window, the $\mathrm{CG}$ is 1 , whereas for any other window functions, the $\mathrm{CG}$ is reduced due to the window smoothly going to zero at the boundaries. CG shows the reduction in signal power. 


\subsection{Incoherent Power Gain}

Averaging of the square of window function w(nT) is called Incoherent Power Gain. It can be computed from the formula

$$
I C G=\frac{1}{N} \sum_{n}[w(n T)]^{2}
$$

ICG gives the accumulated noise power of the window. ICG is Similar to CG, for the rectangular window, the ICG is 1 , whereas for any other window functions, the ICG decreases.

\subsection{Equivalent Noise Band Width}

The ratio between ICG and square of CG is called Equivalent Noise Band Width. It can be computed from the formula

$$
E N B W=\frac{I C G}{[C G]^{2}}=N \frac{\sum_{n}[w(n T)]^{2}}{\left[\sum_{n} w(n T)\right]^{2}}
$$

ENBW determines the capability of a window function w(nT) to extract the signal amplitude from back ground noise. The lower value of ENBW gives better signal extraction from back ground noise. The rectangular window has the best possible value for ENBW equal to 1. All other window functions will have ENBW greater than 1. Since the window function attenuates the signal at interval ends, it reduces the overall signal power. As a consequence of this, the amplitude measured at the DFT bin is not the same as the real amplitude of the signals frequency component at that frequency.

\subsection{Scalloping Loss}

An important consideration related to minimum detectable signal is called Scalloping loss or picket-fence effect. It is another useful parameter, used to obtain the performance of window function. SL can be defined as the ratio between the power gain for a signal frequency component located halfway between DFT bins to the coherent power gain for a signal frequency component located exactly on the DFT bin

$S L=\frac{\left|\sum_{n} w(n T) e^{-j \pi(n / N)}\right|}{\sum_{n} w(n T)}$

\section{WINDOWS APPLIED TO ATMOSPHERIC}

\section{RADAR SIGNALS}

We can apply all fixed length windows and adjustable width windows for atmospheric RADAR signals. Under adjustable width windows, here I am presenting exponential/Cosine Hyperbolic/Polynomial windows for the result analysis and finally we will compare above windows. Wind profile detection of a MST Radar signal meant the measurement of Doppler's of the signal due to scattering of the atmospheric elements. Atmospheric Radar signal meant the signal received by the Radar due to the back scattering property of the atmospheric layers, stratified or turbulent. The back-scattered signal from the atmospheric layers is very small in terms of power with which it was emitted. The received back-scattered signals otherwise called as Radar returns are associated with Gaussian noise. The noise dominates the signal as the distance between the Radar and the target increases and this leads to a decrease in Signal to Noise ratio. This makes the detection of the signal difficult. Doppler profile information is obtained from the power spectrum using Fast Fourier Transform. Frequency characteristics of the back-scattered signals of the Radar are analyzed with power spectrum, which specifies the spectral characteristics of a signal in frequency domain.

The specifications of the RADAR data are given in table.1. The SNR analysis is performed on MST Radar data corresponds to the lower stratosphere obtained from the NARL, Gadanki, India. The Radar was operated in Zenith X, Zenith Y, North, South, West and East directions with an angle of 10 Po from the vertical direction. The data obtained from the six directions are used to carry on the analysis. The algorithm presented below, uses MATLAB to study the effect of " $\alpha$ or $m$ " on the SNR of the Radar returns.

\section{ALGORITHM AND RESULTS}

The implementation scheme is presented here.

a) Compute the window with the specified " $\alpha$ or $\mathbf{~ m " ~}$

b) Taper the radar data with the windows weights specified in (a).

c) Perform the Fourier analysis of the above tapered data [32]-[34].

d) Compute the SNR using the procedure [31]-[34]

e) Compute the Mean Value Below Zero SNR'S (MVBZ) [17]-[18]

f) Compute the Mean Value Above Zero SNR'S (MVAZ) [17]-[18]

g) Update the value of " $\alpha$ or $\mathbf{~ m}$ " and repeat the steps (b) to (f).

The data used in this paper and in MST RADAR centre, Gadanki, India for the computation of mean SNR due to the scattering of signals from the lower stratosphere (up to 30 $\mathrm{Km})$ as given below.

No. of Range Bins $\quad: 150$

No. of FFT points $\quad: 512$

No. of Coherent Integrations $\quad: 64$

No. of Incoherent Integrations $\quad: 1$ 


$\begin{array}{ll}\text { Inter Pulse Period } & : 1000 \mu \mathrm{sec} \\ \text { Pulse Width } & : 16 \mu \mathrm{sec} \\ \text { Beam } & : 10^{\circ}\end{array}$

Table -1: Specifications of the MST RADAR, INDIA (data on which the analysis is Performed)

\begin{tabular}{|l|l|}
\hline Period of Observation & $2008-2010$ \\
\hline Pulse Width & $16 \mu \mathrm{s}$ \\
\hline Range resolution & $150 \mathrm{~m}$ \\
\hline Inter Pulse Period & $1000 \mu \mathrm{s}$ \\
\hline No of Beams-6 & $\mathrm{E} 10 \mathrm{y}, \mathrm{W} 10 \mathrm{y}, \mathrm{Zy}, \mathrm{Zx}, \mathrm{N} 10 \mathrm{x}, \mathrm{S} 10 \mathrm{x}$ \\
\hline No of FFT points & 512 \\
\hline No of incoherent & 1 \\
\hline Max. Doppler Frequency & $3.9 \mathrm{~Hz}$ \\
\hline Maximum Doppler & $10.94 \mathrm{~m} / \mathrm{s}$ \\
\hline Frequency resolution & $0.061 \mathrm{~Hz}$ \\
\hline Velocity resolution & $0.176 \mathrm{~m} / \mathrm{s}$ \\
\hline
\end{tabular}

Comparison of Exponential window, Cosine Hyperbolic window, Polynomial window and Kaiser window in terms of Mean Value Above Zero (MVAZ) and Mean Value Below Zero (MVBZ) towards East, West, North, South, Zenith X and Zenith $\mathrm{Y}$ as shown in table 2.

Table -2: Comparison of Windows in terms of MVAZ and MVBZ

\begin{tabular}{|l|l|l|l|l|}
\hline $\begin{array}{l}\text { Window / } \\
\text { Performan } \\
\text { ce }\end{array}$ & $\begin{array}{l}\text { Exponenti } \\
\text { al } \\
\text { Window } \\
(\alpha=6)\end{array}$ & $\begin{array}{l}\text { Cosine } \\
\text { Hyperbolic } \\
\text { Window }(\alpha= \\
6)\end{array}$ & $\begin{array}{l}\text { Polynomi } \\
\text { al } \\
\text { Window } \\
(\mathrm{m}=4)\end{array}$ & $\begin{array}{l}\text { Kaiser } \\
\text { Windo } \\
\text { w } \\
(\alpha=6)\end{array}$ \\
\hline $\begin{array}{l}\text { MVAZ } \\
\text { East Beam }\end{array}$ & 8.7235 & 8.7237 & 8.9883 & 9.0227 \\
\hline $\begin{array}{l}\text { MVBZ } \\
\text { East Beam }\end{array}$ & -7.3089 & -7.3104 & -6.7513 & $\begin{array}{l}- \\
7.4469\end{array}$ \\
\hline $\begin{array}{l}\text { MVAZ } \\
\text { West } \\
\text { Beam }\end{array}$ & 9.9974 & 9.9951 & 9.3861 & 9.9494 \\
\hline $\begin{array}{l}\text { MVBZ } \\
\text { West } \\
\text { Beam }\end{array}$ & -6.8891 & -6.8909 & -6.7102 & - \\
\hline $\begin{array}{l}\text { MVAZ } \\
\text { North } \\
\text { Beam }\end{array}$ & 12.0574 & 12.2462 & 11.6055 & $\begin{array}{l}11.985 \\
4\end{array}$ \\
\hline $\begin{array}{l}\text { MVBZ } \\
\text { North } \\
\text { Beam }\end{array}$ & -8.2761 & -8.1785 & -8.0110 & - \\
\hline $\begin{array}{l}\text { MVAZ } \\
\text { South } \\
\text { Beam }\end{array}$ & 11.3295 & 11.3258 & 11.1207 & $\begin{array}{l}11.450 \\
9\end{array}$ \\
\hline MVBZ & -6.6630 & -6.6644 & -6.3978 & - \\
\hline
\end{tabular}

\begin{tabular}{|c|c|c|c|c|}
\hline $\begin{array}{l}\text { South } \\
\text { Beam }\end{array}$ & & & & 6.7901 \\
\hline $\begin{array}{l}\text { MVAZ } \\
\text { ZenithX }\end{array}$ & 12.4528 & 12.4634 & 12.3754 & $\begin{array}{l}12.505 \\
6\end{array}$ \\
\hline $\begin{array}{l}\text { MVBZ } \\
\text { ZenithX }\end{array}$ & -7.2073 & -7.2079 & -6.7835 & $\begin{array}{l}- \\
7.4145 \\
\end{array}$ \\
\hline $\begin{array}{l}\text { MVAZ } \\
\text { ZenithY }\end{array}$ & 14.4015 & 14.4070 & 14.1277 & $\begin{array}{l}14.336 \\
2\end{array}$ \\
\hline $\begin{array}{l}\text { MVBZ } \\
\text { ZenithY }\end{array}$ & -6.7303 & -6.7314 & -6.6980 & $\begin{array}{l} \\
6.9176\end{array}$ \\
\hline
\end{tabular}

Performance of Exponential window, Cosine Hyperbolic window, Polynomial window and Kaiser window for different shape parameters $(\alpha$ or $m=1$ to $\alpha$ or $m=8)$ in terms of Coherent Gain (CG), Incoherent Power Gain (ICG), Equivalent Noise Band Width (ENBW) and Scalloping Loss (SL) as shown in Table 3 to Table 6.

Table -3: Performance of Exponential Window

\begin{tabular}{|l|l|l|l|l|}
\hline Parameter & CG & ICG & ENBW & SL \\
\hline$\alpha=1$ & 0.8246 & 0.7068 & 1.0395 & 0.6973 \\
\hline$\alpha=2$ & 0.7068 & 0.5618 & 1.1247 & 0.7453 \\
\hline$\alpha=3$ & 0.6235 & 0.4768 & 1.2267 & 0.7828 \\
\hline$\alpha=4$ & 0.5618 & 0.4206 & 1.3325 & 0.8120 \\
\hline$\alpha=5$ & 0.5144 & 0.3802 & 1.4366 & 0.8351 \\
\hline$\alpha=6$ & 0.4768 & 0.3495 & 1.5371 & 0.8536 \\
\hline$\alpha=7$ & 0.4462 & 0.3251 & 1.6334 & 0.8686 \\
\hline$\alpha=8$ & 0.4206 & 0.3052 & 1.7254 & 0.8809 \\
\hline
\end{tabular}

Table -4: Performance of Cosine Hyperbolic Window

\begin{tabular}{|l|l|l|l|l|}
\hline Parameter & CG & ICG & ENBW & SL \\
\hline$\alpha=1$ & 0.8784 & 0.7830 & 1.0147 & 0.6739 \\
\hline$\alpha=2$ & 0.7253 & 0.5785 & 1.0995 & 0.7337 \\
\hline$\alpha=3$ & 0.6282 & 0.4795 & 1.2148 & 0.7787 \\
\hline$\alpha=4$ & 0.5630 & 0.4210 & 1.3281 & 0.8108 \\
\hline$\alpha=5$ & 0.5147 & 0.3803 & 1.4352 & 0.8348 \\
\hline$\alpha=6$ & 0.4769 & 0.3495 & 1.5366 & 0.8535 \\
\hline$\alpha=7$ & 0.4462 & 0.3251 & 1.6332 & 0.8685 \\
\hline$\alpha=8$ & 0.4206 & 0.3052 & 1.7253 & 0.8809 \\
\hline
\end{tabular}

Table -5: Performance of Polynomial Window

\begin{tabular}{|l|l|l|l|l|}
\hline Parameter & CG & ICG & ENBW & SL \\
\hline $\mathrm{m}=1$ & 0.8843 & 0.7928 & 1.0127 & 0.6633 \\
\hline $\mathrm{m}=2$ & 0.7432 & 0.6013 & 1.0884 & 0.7337 \\
\hline $\mathrm{m}=3$ & 0.6312 & 0.5546 & 1.4171 & 0.7617 \\
\hline $\mathrm{m}=4$ & 0.5719 & 0.4799 & 1.4673 & 0.8011 \\
\hline $\mathrm{m}=5$ & 0.5230 & 0.4075 & 1.4849 & 0.8348 \\
\hline $\mathrm{m}=6$ & 0.4923 & 0.3633 & 1.4991 & 0.8412 \\
\hline $\mathrm{m}=7$ & 0.4513 & 0.3297 & 1.6191 & 0.8521 \\
\hline $\mathrm{m}=8$ & 0.4398 & 0.3292 & 1.7018 & 0.8713 \\
\hline
\end{tabular}


Table -6: Performance of Kaiser Window

\begin{tabular}{|l|l|l|l|l|}
\hline Parameter & CG & ICG & ENBW & SL \\
\hline$\alpha=1$ & 0.9280 & 0.8651 & 1.0047 & 0.6576 \\
\hline$\alpha=2$ & 0.7948 & 0.6618 & 1.0476 & 0.7038 \\
\hline$\alpha=3$ & 0.6832 & 0.5311 & 1.1377 & 0.7506 \\
\hline$\alpha=4$ & 0.6026 & 0.4534 & 1.2485 & 0.7888 \\
\hline$\alpha=5$ & 0.5438 & 0.4026 & 1.3613 & 0.8183 \\
\hline$\alpha=6$ & 0.4991 & 0.3660 & 1.4695 & 0.8410 \\
\hline$\alpha=7$ & 0.4637 & 0.3380 & 1.5720 & 0.8589 \\
\hline$\alpha=8$ & 0.4349 & 0.3157 & 1.6690 & 0.8732 \\
\hline
\end{tabular}

Variation in CG/ICG and ENBW/SL due to increase in window shape parameter " $\alpha$ or $m$ " for Exponential window shown in Fig. 1(a) to Fig. 1(b), for Cosine Hyperbolic window shown in Fig. 2(a) to Fig. 2(b), for Polynomial window shown in Fig. 3(a) to Fig. 3(b), and for Kaiser window shown in Fig. 4(a) to Fig. 4(b).

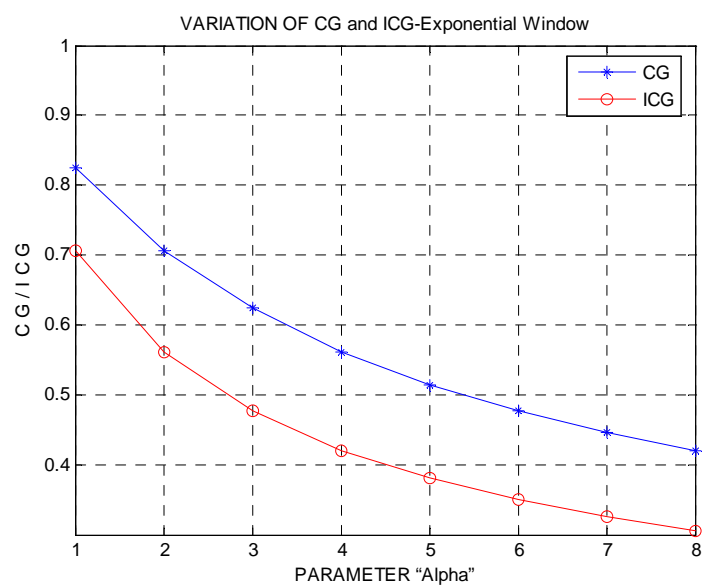

Fig. 1(a)

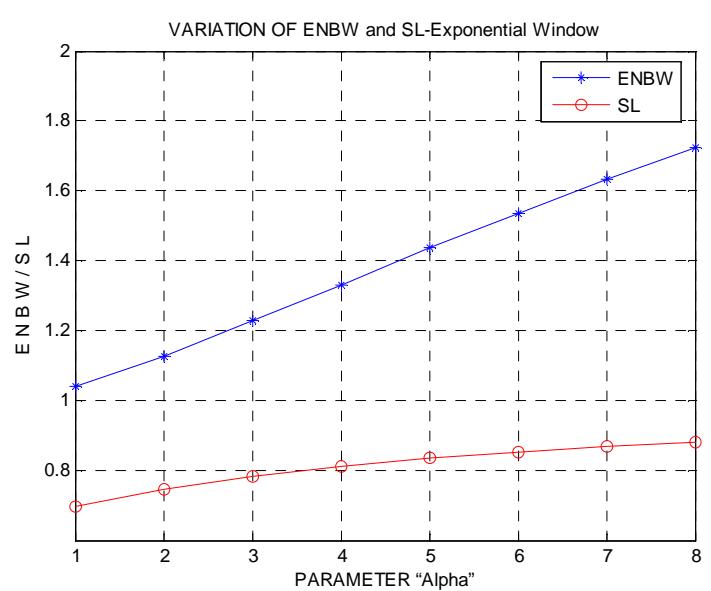

Fig. 1(b)

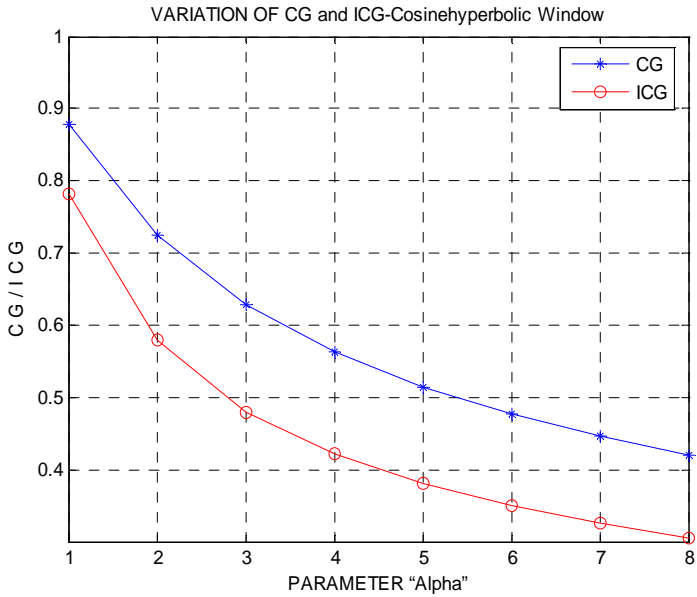

Fig. 2(a)

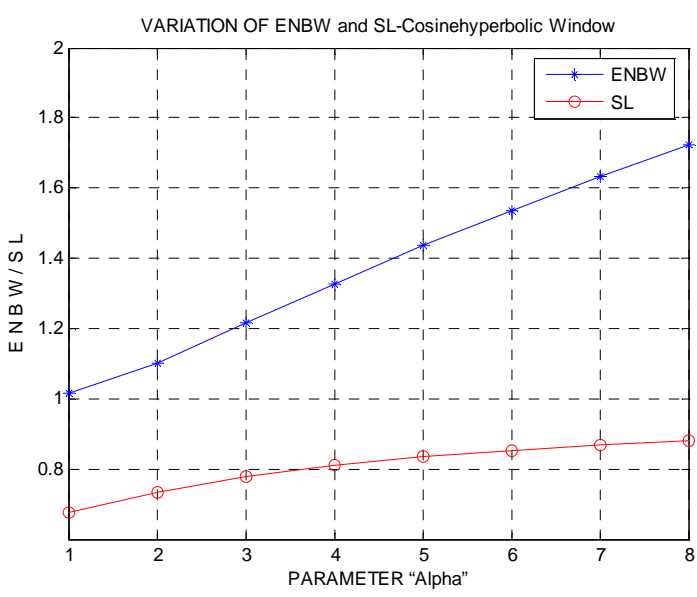

Fig. 2(b)

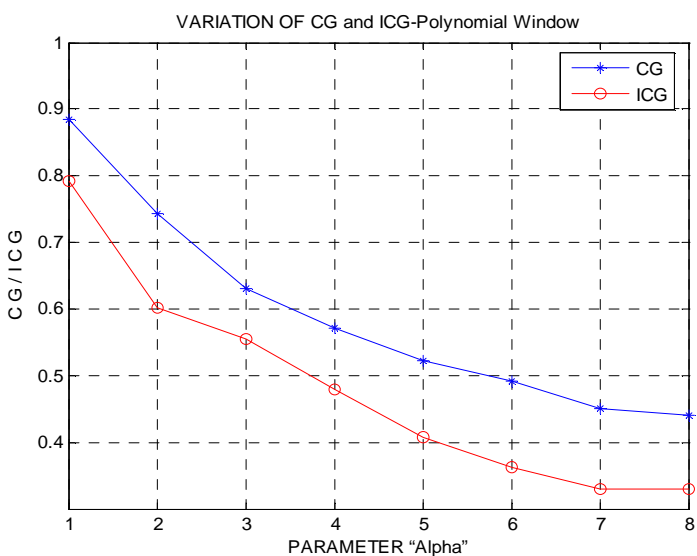

Fig. 3(a) 


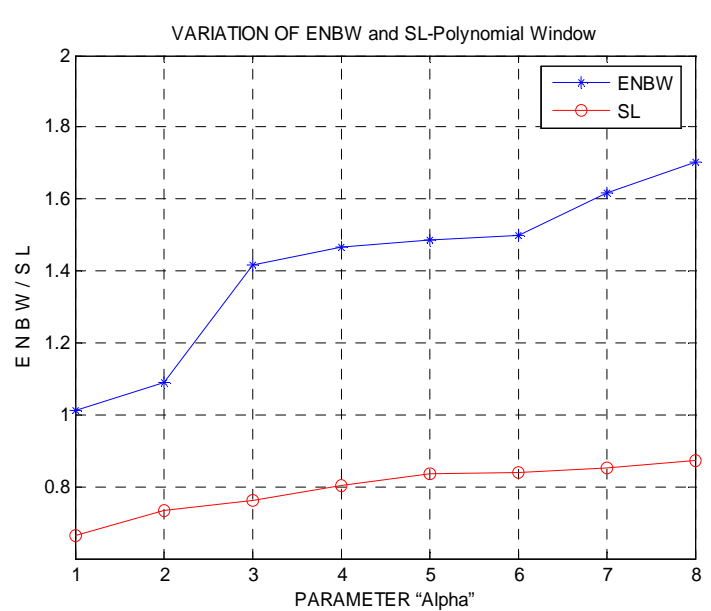

Fig. 3(b)

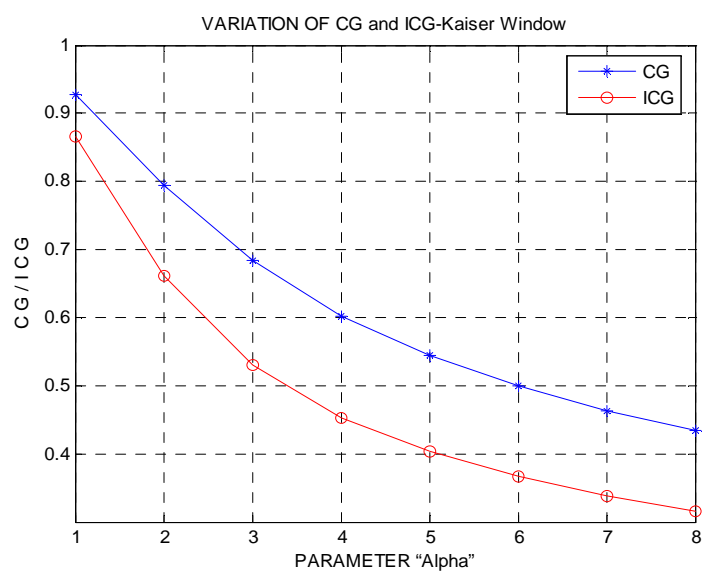

Fig. 4(a)

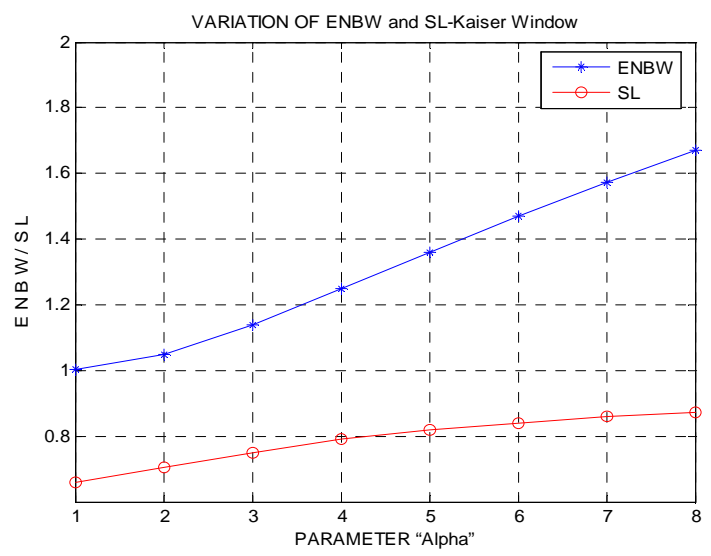

Fig. 4(b)

\section{DISCUSSION AND CONCLUSION}

The SNR computation [31[-[34] for the six sets of Radar data (East, West, North, South, Zenith X and Zenith Y beams) is carried on and presented in table. 2 and the performance analysis is presented in table. 3 to table.6. The Mean Value of Below Zero SNR'S (MVBZ), in all the cases increases with the shape parameter " $\alpha$ or $m$ ". The increase in MVBZ continues up to certain value of the shape parameter now onwards called optimum " $\alpha$ " value. Further increase in the shape parameter " $\alpha$ ", no appreciable change in MVBZ SNR is observed.

This fact clearly demonstrates that even if the sidelobe reduction, which contributes the SNR improvement at the cost of main lobe width shows the improvement in SNR. Further increasing the " $\alpha$ or $m$ " value still decreases the side lobe level but due to the increase in the main lobe width compensates the increase in the MVBZ SNR. Hence the MVBZ SNR value attains almost constant in all the six sets of Radar data. On the other hand in all the six-sets of data, there is no appreciable change in the Mean Value of the Above Zero SNR'S (MVAZ) with sidelobe attenuation " $\alpha$ or m". These results are important since the back-scattered signal from the middle and uppermost bins are very week and improvement in SNR is highly desirable in spectral estimation. Therefore selection of the shape parameter plays important role in achieving SNR improvement.

\section{ACKNOWLEDGEMENTS}

The authors are thankful to Dr. S. Jayaraman, Director, NARL, and Gadanki, India for permitting to use the facilities at the Radar centre. The first author is thankful to Dr. L.S.S Reddy, Director Lakireddy Bali Reddy College of Engineering, mylavaram for his encouragement towards research work and interest shown in the present work. Second author is thankful to the Management of Srikalahasteeswara Swamyvari Devasthanam, Srikalahasthi.

\section{REFERENCES}

[1] FREDRIC J.HARRIS, "On the Use of Windows for Harmonic Analysis with the Discrete Fourier Transform", Proc. IEEE, Vol.66, No.1, PP.51-.83, Jan.1978.

[2] Kay, S.M., "Modern Spectral Estimation", PrenticeHall, Inc., Englewood Cliffs, NJ ,1988.

[3] Marple.SL,Jr.'Digital Spectral Analysis with Applications", Prentice-Hall Inc., Englewood Cliffs, NJ, 1987.

[4] Ronald F.Woodman, "Spectral moment estimation in MST radars"Radio Science,Vol.20,No.6,PP.11851195,Jun 1985

[5] Kemal Avci and Arif Nacaroglu, "A New Window Based on Exponential Function", Research in 
Microelectronics and Electronics, PP. 69-72, 2008, Digital Object Identifier: 10.1109/RME.2008.4595727.

[6] Kemal Avci and Arif Nacaroglu, "Cosine Hyperbolic Window Family with its Application to FIR Filter Design", International conference on Information and Communication Technologies: From Theory to Applications, PP.1-6, 2008. ICTTA 2008. Digital Object Identifier: 10.1109/ICTTA.2008.4530047.

[7] Puneet Singla,Tarunraj Singh"Desired Order of Continuous Polynomial Time Window Functions for Harmonic Analysis", IEEE Transactions on Instrumentation and Measurement, Vol.59, No.9, 24752481 September 2010,

[8] V. Oppenheim and Ronald W.Schafer,"'Descrite Time Signal Processing" Prentice Hall International. Inc, 1998.

[9] E. Torbet, M. J. Devlin, W. B. Dorwart, et al., “A measurement of the angular power spectrum of the microwave background made from the high Chilean Andes," The Astrophysical Journal, Vol.521, No.2, PP.79-82, Aug 1999.

[10] Picard.B, Anterrieu.E, Caudal.G, Waldteufel.P, "Improved windowing functions for Y-shaped synthetic aperture imaging radiometers" in Proc. IEEE International Geoscience and Remote Sensing Symposium (IGARSS '02), Vol. 5, PP.2756-2758, Toronto, Canada, June 2002.

[11] PETER LYNCH, "The Dolph-Chebyshev Window:A Simple Optimal Flter," Monthly Weather Review, Vol. 125, PP. 655-660, 1997.

[12] D.A.Hooper, "Signal and noise level estimation for narrow spectral width returns observed by the Indian MST radar", Radio Science, Vol.34, No.4, PP.859-870, 1999.

[13] Andrwas Antoniou,"Digital Filters Analysis, Design and Applications", Tata McGraw-Hill, 1999.

[14] ASR Reddy, et al, "Two Level Multiple Taper Spectral Analysis Applied to MST Radar Signals", Journal of the Institution of Engineers(India),Vol.87, PP.61-66, July 2006.

[15] Reddy. G.H. et al, "Effect of Windowing on SNR of MST Radar Signals", Engineering Today, Vol.9, No.11, PP.22-26, 2007.

[16] Reddy .G.H. et al, "Effect of Windowing on SNR of MST Radar Signals", Far East Journal of Electronics and Communications, Vol.2, No.1, PP.89-98, 2008.

[17] Reddy .G.H. et al, "The Effect of ' $\beta$ ' in Kaiser Window on the SNR of MST Radar Signals", Asian Journal of scientific Research, ISSN:1992-1454,Vol.1, No.3, PP.203-212, 2008.

[18] Reddy .G.H. et al, "Improved SNR of MST Radar Signals: Gaussian Window parameter", JNTU Technology Spectrum, Vol.3, No.1, PP.97-104, 2010.

[19] B.Ramesh Reddy, et al "The effect of shape parameter $\alpha$ in Dolph-Chebyshev Window on the SNR improvement of MST RADAR Signals" International
Journal of Electronics and Communication Technology, ISSN: 2230-7109(online), 2230-9543(print), Vol.3, issue.1, Jan-March 2012, PP.7-11.

[20] B.Ramesh Reddy, et al "SNR improvement and Computational advantage of Exponential window over Kaiser window on MST RADAR signals" International Journal of Advanced Research in Technology, ISSN:6602-3127,Vol.2, Issue.2, 2012, PP.43-53.

[21] B.Ramesh Reddy, et al "Improved SNR of MST RADAR signals by Cosine Hyperbolic window over Kaiser window" International Journal of Electronics Communication and Computer Engineering, ISSN: 2249-071X, Vol.3, Issue.1, 2012, PP.169-173.

[22] B.Ramesh Reddy, et al "Polynomial window functions: SNR improvement of MST RADAR signals" Journal of Innovation in Electronics and Communication, ISSN: 2249-9946,Vol.2, Issue.2, Jan-2012, PP.89-93.

[23] J. F. Kaiser, "Nonrecursive digital filter design using $\mathrm{I}_{0}$ -sinh window function." in Proc. IEEE Int. Symp. Circuits and Systems (ISCAS'74), PP.20-23, San Francisco, Calif, USA, April 1974.

[24] Saramaki.T, "A class of window functions with nearly minimum side lobe energy for designing FIR filters" in Proc. IEEE Int. Symp. Circuits and Systems (ISCAS '89), Vol. 1, PP. 359-362, Portland, Ore, USA, May 1989.

[25] C.L.DOLPH, "A current distribution for broadside arrays which optimizes the relationship between beamwidth and side-lobe level" Proc. IRE, Vol.34, PP.335-348, June 1946.

[26] A.G.Deczky, "Unispherical Windows," in Proc. IEEE Int. Symp. Circuits and Systems (ISCAS '01), Vol.2, PP.85-88, Sydney, NSW, Australia, May 2001.

[27] Stuart W.A Bergen and Andreas Antoniou, "Design of Ultraspherical Window Functions with Prescribed Spectral Characteristics", EURASIP Journal on Applied Signal Processing Vol.13, PP.2053-2065, 2004.

[28] Saramaki.T, "Finite Impulse Response Filter Design," in Hand book for Digital digital Processing, S. K. Mitra and J. F. Kaiser, Eds., Wiley, New York, NY, USA, 1993.

[29] Rabiner.L.R, McClellan.J.H and Parks.T.W "FIR Digital Filter Design Techniques Using Weighted Chebyshev Appr., Proc. IEEE, Vol.63, Issue.4, PP.595 -610, April 1975.

[30] Streit.R "A two-parameter family of weights for nonrecursive digital filters and antennas," IEEE Trans. Acoustics, Speech and Signal Processing, Vol.32, Issue.1, PP.108-118, Feb 1984.

[31] PETER H.HILDEBRAND and R. S. SEKHON "Objective determination of the noise level in Doppler spectra", Journal of Applied Meteorology, Vol.13, PP.808-811, Oct 1974.

[32] V.K Anandan, "Signal and Data processing Techniques for Atmospheric Radars", Ph.D. thesis, S.V. University, Tirupati. 1999. 
[33] V.K Anandan, "Atmospheric Data Processor Technical User reference manual", NMRF publication, Tirupati, 1998.

[34] S,K Mitra, "Digital Signal Processing- A Computer Based Approach", Tata McGraw-Hill, 1998

\section{BIOGRAPHIES}

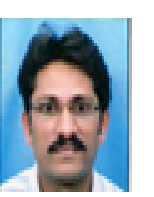

First Author, Prof B Ramesh Reddy received the B.Tech., degree in Electronics and Communication Engineering in the year 1995 from NBKRIST, SV University, Tirupati, Andhra Pradesh, India. He obtained M.E., degree in Electronics in the year 2002 from UVCE, Bangalore, Karnataka, India. Now he is pursuing $\mathrm{PhD}$ in the area "Improvement in SNR of MST RADAR Signals" at JNTU, Hyderabad, India. He has been working as Professor and HOD in the department of Electronics and Communication Engineering in Lakireddy Balireddy College of Engineering, Mylavaram, Andhra Pradesh, India. He has 17 years of teaching experience.

Second Author, Dr. A. Subbarami Reddy, Research Supervisor for the first author's work, is working as Principal in Sri Kalahasteeswara Institute of Technology, Chittoor Dist, Andhrapradesh, India.

Third Author, Dr. P. Chandrashekar Reddy, co-supervisor for the first author's work, is working as Professor of Coordination, JNTU, Hyderabad, Andhra Pradesh, India 